\title{
Frequency and risk factors for the development of drug related problems among rheumatoid arthritis patients
}

\author{
Sujit Kumar Sah ${ }^{\text {, }}$, Subramanian Ramaswamy ${ }^{\mathrm{b}}$, Madhan Ramesh ${ }^{\mathrm{a}, *}$ \\ ${ }^{a}$ Department of Pharmacy Practice, JSS College of Pharmacy, JSS Academy of Higher Education and Research, SS Nagar, Mysuru, 570015, Karnataka, India \\ ${ }^{\mathrm{b}}$ Department of Rheumatology \& Immunology, JSS Medical College, JSS Academy of Higher Education and Research, SS Nagar, Mysuru, 570015, Karnataka, India
}

\section{A R T I C L E I N F O}

\section{Keywords:}

Rheumatoid arthritis

Drug related problems

Clinical pharmacist

Interventions

Risk factors

\begin{abstract}
A B S T R A C T
Background: Rheumatoid arthritis (RA) patients are at high risk for development of drug related problems (DRPs) due to multiple drug use. This study aimed to estimate the frequency and risk factors for the development of drug related problems among RA patients in Indian setting.

Methods: A prospective cohort study was carried out for twenty-two months in a tertiary care teaching hospital. Patients who met study eligibility criteria were randomised either into intervention or usual care group. All the patients' data were screened for the presence of DRPs. Identified DRPs were categorized into problems and their causes using Pharmaceutical Care Network Europe (PCNE V8.02) DRP Classification system. Clinical pharmacists proposed interventions to resolve DRPs in intervention group.

Results: A total of 320 RA patients [Intervention group, $n=160$ and usual care group, $n=160$ ] were enrolled in this study. Overall, 463 DRPs were identified among $88.4 \%$ of patients, and frequency of DRPs was 1.6 per patient. Treatment safety (41.2\%) and patient related factors $(28.2 \%)$ was the most common category and cause of DRPs respectively. Advanced age and polypharmacy were the common risk factors identified for the development of DRPs.

Conclusion: This study revealed DRPs are common among RA patients and those are related to the treatment safety and efficacy. Clinical pharmacists' provided interventions had significant impact on DRPs resolution among RA patients.
\end{abstract}

\section{Introduction}

Rheumatoid arthritis (RA) is a chronic autoimmune disorders caused due to failure of immune responses against own immunity. ${ }^{1}$ This is characterized by pain, swelling, tender, warm and stiffness of the joints. Progressive inflammation of joints in RA can leads to the joint deterioration and disability, and eventually increased the morbidity and economic burden to the patient. ${ }^{2}$ The prevalence of RA in Indian population ranges from $0.28 \%$ to $0.7 \%$ and around $0.5 \%$ to $1 \%$ in global population. ${ }^{3,4}$ The incidence of RA is relatively three times higher in females as compared to the males. Genetic factors or combination of genetic and environmental factors such as female gender, hormonal changes, family history and tobacco smoking believed to be associated with the development and prognosis of RA. ${ }^{5}$ Presently, management with medications are a mainstay for the treatment of RA, but this has become challenging due to unwanted adverse effects and often expensive. ${ }^{6}$

Most frequently prescribed medications to manage RA includes nonsteroidal anti-inflammatory drugs (NSAIDs), corticosteroids and disease-modifying anti-rheumatic drugs (DMARDs). ${ }^{7}$ An intensive and complex drug regimens may requires upon high disease activity and low remission rate for short to long period of time. ${ }^{8}$ This increases the risk of DRPs. Drug related problem (DRP) is defined as an event or circumstance involving drug therapy that actually or potentially interferes with desired health outcomes, that occurred at any stage of the treatment. ${ }^{9}$ The occurrence of DRPs may associated with the risk of patient harm, reduce patients' quality of life and economic loss. ${ }^{10}$ Thus, timely identification and resolution of DRPs become essential to enhance patient outcomes. Clinical pharmacist can play a critical role for the enhancement of patient outcomes by actively participate on the detection of DRPs and their management. Clinical pharmacist is well known to provide individual pharmaceutical care by suggesting safest and cost-effective alternatives to optimize the pharmacotherapy. ${ }^{11}$ Furthermore, multiple studies revealed that collaborative care of clinical pharmacist with treating physician had higher acceptance rate of

\footnotetext{
* Corresponding author.

E-mail address: mramesh@jssuni.edu.in (M. Ramesh).
} 
clinical pharmacist interventions and significant impact on the resolution of DRPs. ${ }^{12,13}$

Limited study found that revealed the occurrence of DRPs in RA patients, ${ }^{14}$ but the participation of clinical pharmacist in the detection of DRPs and their management is still unpublished. Furthermore, the prevalence of DRPs among Indian population and the impact of clinical pharmacist in detection and resolution of DRPs is still uncertain. Hence, we aimed to conduct this study to estimate the frequency and risk factors for the development of drug related problems among rheumatoid arthritis patients in Indian setting.

\section{Methods}

This prospective cohort study was carried out over a period of twenty-two months (July 2019 to April 2021) at a tertiary care teaching hospital in southern India after obtaining the approval from Institutional Human Ethics Committee, meeting held on $10^{\text {th }}$ June 2019. Rheumatoid arthritis patient of any gender and aged above 16 years, admitted to the hospital were screened for the study eligible criteria and were enrolled in this study after obtaining their written informed consent. Patients' demographic data, clinical manifestation, past medical and medication history, current diagnosis and medications, and relevant laboratory data, were collected and documented in a suitably designed data collection form.

Study participants were categorized either into intervention group or into usual care group following simple randomization technique. Participants in either group were screened for the presence of drug-related problems (DRPs). Participants in the intervention group received pharmacists' interventions to resolve identified DRPs, in addition to the usual care. Whereas, participants in the usual care group received only usual care by physician and nurses. However, their treatment chart was reviewed on daily basis by the clinical pharmacist to identify DRPs and to document the outcomes of DRPs till discharge.

The identified DRPs were verified through consulting international guidelines for the management of rheumatoid arthritis, ${ }^{15}$ pharmacist practice guidelines, ${ }^{16}$ recent publications and electronic databases such as Micromedex ${ }^{\circledR}$ and Medscape ${ }^{\circledR}$. DRPs were categorized into their problems and associated causes by adopting Pharmaceutical Care Network Europe (PCNE V8.02) DRP classification system. ${ }^{17}$ Further, Clinical pharmacist planned the interventions following systemic search and critical appraisal of available best evidences to resolve the DRPs. All the identified DRPs notified and possible interventions to resolve the DRPs were discussed with the multidisciplinary care team (MDCT) on real-time basis within 24-48 h. The MDCT included the treating rheumatologist, two clinical pharmacists, and two nursing staff. The clinical pharmacist interventions were implemented after collective decision taken by the MDCT. The clinical significance of the accepted interventions was evaluated and categorized adopting Alderman's classification system. ${ }^{18}$ Patient in the intervention group were followed till discharge to document the outcomes of DRPs upon implemented interventions. The identified DRPs in the intervention group and usual care group were compared with respect to their frequency, nature and causes. The impact of clinical pharmacists' interventions on outcomes of DRPs was assessed among participants in the intervention group.

The descriptive data were analysed and expressed as frequencies and percentage values. A chi-square test $\left(\chi^{2}\right)$ was used to evaluate the association between categorical variables among groups. Multiple logistic regression analysis was performed to identify the risk of DRPs. All the statistical analysis was carried out using SPSS V25®.

\section{Results}

A total of 320 patients who met the study inclusion criteria were enrolled. Participants were equally divided into intervention group $(\mathrm{n}=$ $160)$ and usual care group $(n=160)$. A female predominance was observed in both the groups [Intervention group: 128/160 (80\%) and usual care group: 120/160 (75\%)]. The mean age of study participants was $48.04 \pm 17.13$ years in the intervention group and $49.12 \pm 20.66$ years in the usual care group. The demographic details are presented in Table 1. A majority of patients were taking more than five drugs in both the groups [Intervention group: 128/160 (80\%); Usual care group: 116/ $160(72.5 \%)]$. In majority of the study participants [Intervention group: 75/160 (46.8\%); Usual care group: 86/160 (53.7\%)] the duration of rheumatoid arthritis was $1-5$ years. Hyperlipidaemia [137, 42.8\%],

Table 1

Demographic details of the study participants $(n=320)$.

\begin{tabular}{|c|c|c|c|c|}
\hline Variables & Parameters & $\begin{array}{l}\text { Intervention } \\
\text { group }[\mathrm{n}= \\
160,(100 \%)]\end{array}$ & $\begin{array}{l}\text { Usual care } \\
\text { group [n } \\
=160 \text {, } \\
(100 \%)]\end{array}$ & $\begin{array}{l}\text { Total [n } \\
=320 \\
(100 \%)]\end{array}$ \\
\hline \multirow[t]{2}{*}{ Gender } & Male & $32(20 \%)$ & $40(25 \%)$ & $\begin{array}{l}72 \\
(22.5 \%)\end{array}$ \\
\hline & Female & $128(80 \%)$ & $120(75 \%)$ & $\begin{array}{l}248 \\
(77.5 \%)\end{array}$ \\
\hline \multirow[t]{5}{*}{$\begin{array}{l}\text { Age distribution } \\
\text { (in years) }\end{array}$} & $<19$ & $12(7.5 \%)$ & $10(6.2 \%)$ & $\begin{array}{l}22 \\
(6.8 \%)\end{array}$ \\
\hline & $19-40$ & $55(34.4 \%)$ & $\begin{array}{l}43 \\
(23.8 \%)\end{array}$ & $\begin{array}{l}98 \\
(30.6 \%)\end{array}$ \\
\hline & $41-60$ & $60(37.5 \%)$ & $\begin{array}{l}70 \\
(43.7 \%)\end{array}$ & $\begin{array}{l}130 \\
(40.6 \%)\end{array}$ \\
\hline & $61-80$ & $25(15.6 \%)$ & $\begin{array}{l}30 \\
(18.7 \%)\end{array}$ & $\begin{array}{l}55 \\
(17.2 \%)\end{array}$ \\
\hline & $>80$ & $8(5 \%)$ & $7(4.3 \%)$ & $\begin{array}{l}15 \\
(4.6 \%)\end{array}$ \\
\hline \multirow[t]{3}{*}{ Social habits } & Alcoholic & $10(6.2 \%)$ & $15(9.3 \%)$ & $\begin{array}{l}25 \\
(7.8 \%)\end{array}$ \\
\hline & Smoker & 19 (11.9\%) & $24(15 \%)$ & $\begin{array}{l}43 \\
(13.4 \%)\end{array}$ \\
\hline & Both & $11(6.8 \%)$ & $08(5 \%)$ & $\begin{array}{l}19 \\
(5.9 \%)\end{array}$ \\
\hline \multirow[t]{3}{*}{$\begin{array}{l}\text { Body Mass Index } \\
\left(\mathrm{Kg} / \mathrm{m}^{2}\right)\end{array}$} & $\leq 18.5-24.9$ & $57(35.6 \%)$ & $\begin{array}{l}73 \\
(45.6 \%)\end{array}$ & $\begin{array}{l}130 \\
(40.6 \%)\end{array}$ \\
\hline & $25-29.9$ & 75 (46.8\%) & $\begin{array}{l}66 \\
(41.2 \%)\end{array}$ & $\begin{array}{l}141 \\
(44.0 \%)\end{array}$ \\
\hline & $\geq 30$ & $28(17.5 \%)$ & $\begin{array}{l}21 \\
(13.1 \%)\end{array}$ & $\begin{array}{l}49 \\
(15.3 \%)\end{array}$ \\
\hline \multirow[t]{5}{*}{$\begin{array}{l}\text { Educational } \\
\text { status }\end{array}$} & $\begin{array}{l}\text { Graduate or } \\
\text { above }\end{array}$ & $1(0.6 \%)$ & $4(2.5 \%)$ & $5(1.5 \%)$ \\
\hline & $\begin{array}{l}\text { Intermediate/ } \\
\text { diploma or High } \\
\text { school } \\
\text { certificate }\end{array}$ & $15(9.3 \%)$ & $\begin{array}{l}17 \\
(10.6 \%)\end{array}$ & $32(10 \%)$ \\
\hline & $\begin{array}{l}\text { Middle school } \\
\text { certificate }\end{array}$ & $21(13.1 \%)$ & $\begin{array}{l}30 \\
(18.7 \%)\end{array}$ & $\begin{array}{l}51 \\
(15.9 \%)\end{array}$ \\
\hline & $\begin{array}{l}\text { Primary school } \\
\text { certificate }\end{array}$ & $38(23.7 \%)$ & $\begin{array}{l}47 \\
(29.3 \%)\end{array}$ & $\begin{array}{l}85 \\
(26.5 \%)\end{array}$ \\
\hline & Uneducated & $85(53.1 \%)$ & $\begin{array}{l}62 \\
(38.7 \%)\end{array}$ & $\begin{array}{l}147 \\
(45.9 \%)\end{array}$ \\
\hline \multirow[t]{5}{*}{$\begin{array}{l}\text { Occupational } \\
\text { status }\end{array}$} & $\begin{array}{l}\text { Professional and } \\
\text { Semi- } \\
\text { professional }\end{array}$ & $1(0.6 \%)$ & $4(2.5 \%)$ & $5(1.5 \%)$ \\
\hline & $\begin{array}{l}\text { Clerical, shop } \\
\text { owner, skilled } \\
\text { worker }\end{array}$ & $26(16.2 \%)$ & $32(20 \%)$ & $\begin{array}{l}58 \\
(18.1 \%)\end{array}$ \\
\hline & Semi-skilled & 31 (19.3\%) & $\begin{array}{l}20 \\
(12.5 \%)\end{array}$ & $\begin{array}{l}51 \\
(15.9 \%)\end{array}$ \\
\hline & $\begin{array}{l}\text { Unskilled } \\
\text { worker }\end{array}$ & $27(16.8 \%)$ & $\begin{array}{l}44 \\
(27.5 \%)\end{array}$ & $\begin{array}{l}71 \\
(22.2 \%)\end{array}$ \\
\hline & Unemployed & $75(46.8 \%)$ & $\begin{array}{l}60 \\
(37.5 \%)\end{array}$ & $\begin{array}{l}135 \\
(42.2 \%)\end{array}$ \\
\hline \multirow[t]{5}{*}{$\begin{array}{l}\text { Socioeconomic } \\
\text { status }\end{array}$} & Upper class & $13(8.1 \%)$ & $8(5 \%)$ & $\begin{array}{l}21 \\
(6.5 \%)\end{array}$ \\
\hline & $\begin{array}{l}\text { Upper-middle } \\
\text { class }\end{array}$ & $20(12.5 \%)$ & $\begin{array}{l}17 \\
(10.6 \%)\end{array}$ & $\begin{array}{l}37 \\
(11.5 \%)\end{array}$ \\
\hline & $\begin{array}{l}\text { Lower middle } \\
\text { class }\end{array}$ & $33(20.6 \%)$ & $48(30 \%)$ & $\begin{array}{l}81 \\
(25.3 \%)\end{array}$ \\
\hline & $\begin{array}{l}\text { Upper lower } \\
\text { class }\end{array}$ & $68(42.5 \%)$ & $56(35 \%)$ & $\begin{array}{l}124 \\
(38.7 \%)\end{array}$ \\
\hline & Lower class & $26(16.2 \%)$ & $\begin{array}{l}31 \\
(19.4 \%)\end{array}$ & $\begin{array}{l}57 \\
(17.8 \%)\end{array}$ \\
\hline
\end{tabular}

* All differences were not statistically significant $(\mathrm{p}>0.05)$. 
hypertension [90, 28.1\%] and type 2 diabetes mellitus [80, 25\%] were the most common comorbidities observed among the study patients. The details of clinical characteristics of study participants are presented in Table 2 . There were no statistically significant differences observed both in demographic as well as clinical variables between participants in the intervention and usual care groups.

The average number of drugs prescribed per patient in intervention group and usual care group was 9.4 [1504/160] and 8.9 [1424/160] respectively. Overall, more than two-third $(283 / 320,88.4 \%)$ of the study population experienced at least one DRP. Among which $90.6 \%$ $(145 / 160)$ and $86.2 \%(138 / 160)$ of participants in intervention and usual care group experienced at least one DRP respectively. A total of 463 DRPs were observed in 283 patients. Accordingly, the frequency of DRPs in our study was 1.6 per patient. The frequency of DRPs was almost equally distributed among participants in intervention group [242/145, 1.6 per patient] and the usual care group [221/138, 1.6 per patient].

Treatment safety was the most frequent [Overall: 191/463, (41.2\%); Intervention group: 101/242 (41.9\%); Usual care group: 90/221 (40.7\%)] category of DRP identified in our study, followed by treatment effectiveness [Overall: 183/463, (39.5\%); Intervention group: 96/242 (39.6\%); Usual care group: 87/221 (39.3\%)].

We observed more than one cause for some of the DRPs. A total of 528 causes [Intervention group: 277 causes for 242 DRPs; Usual care group: 251 causes for 221 DRPs] were recognized for 463 DRPs. Among seven primary domains of causes for DRPs recognized in our study, the most frequent [Overall: 149/528, (28.2\%); Intervention group: 82/277 (29.6\%); Usual care group: 67/251 (26.6\%)] domain was patientrelated followed by drug selection [Overall: 132/528, (25\%); Intervention group: 70/277 (25.2\%); Usual care group: 62/251 (24.7\%)]. The details of various categories and causes of DRPs identified are presented in Table 3.

The clinical pharmacists' interventions were proposed for all the 277 causes recognized for the identified DRPs in the intervention group. A majority of the clinical pharmacists' interventions proposed were at patient level [124 (44.7\%)], followed by drug [103 (37.1\%)] and prescriber levels [50 (18\%)]. Of which 253, interventions were accepted and implemented. Accordingly, the acceptance rate of the clinical pharmacists' interventions in our study was $91.3 \%$. A majority [114/ $253,45 \%]$ of the accepted interventions were moderate, followed by minor $[85 / 253,33.5 \%]$ and major $[n=54 / 253,21.3 \%]$ in their clinical significance.

Outcomes of DRPs: In this study, the implemented clinical pharmacist interventions in intervention group resolved of [217/225, 96.4\%] DRPs and $[8 / 225,3.5 \%]$ DRPs were unresolved or continued. In control group, the frequency of DRPs resolved was lower [98/221, 44.3\%] as compared to the DRPs not resolved or continued [123/221, 55.6\%]. The difference in resolved DRPs in intervention group was highly statistically significant $(\mathrm{p}<0.0001)$ as compared to the control group.

Predictors for DRPs: Application of multiple logistic regression shows that patient age group between 61 to 80 years [OR: $8.82,95 \% \mathrm{Cl}$ : 2.34-33.23, $\mathrm{p}=0.0013$ ], patient receiving more than 5 drugs (polypharmacy) [OR: $8.20,95 \% \mathrm{Cl}: 3.91-17.17, \mathrm{p}<0.0001$ ] and number of comorbidities ( $\geq 3$ ) [OR: 5.13 , 95\% Cl: $2.07-12.67, \mathrm{p}=0.0004$ ] were major three risk factors that significantly associated with the development of DRPs. The details in the risk factor associated with the development of DRPs are presented in Table 4.

\section{Discussion}

This is the first prospective cohort study that explored the frequency and risk factors for DRPs among hospitalized RA patients in Indian settings. The overall frequency of DRPs was 1.6 per patient, in both intervention and usual care groups. This finding was compared with a retrospective study conducted among RA patients by Ma SN et al., reported frequency of 1.5 DRPs per patient. ${ }^{14}$ There are many studies conducted in patients with other clinical conditions that reported the frequency of DRPs either equal or different than our findings. ${ }^{19,20}$ These differences are mostly due to the variation in the sample size, study design, age of the study population, extent of involvement by clinical pharmacist, polypharmacy and presence of other co-morbid conditions.

The most frequent category of DRPs observed in both intervention and usual care groups of our study was related to treatment safety that is possible occurring of adverse drug event. Treatment effectiveness was the second most frequent category of DRPs observed. However, Ma SN et al., observed, adverse reactions as the most frequent category of DRPs in their study. ${ }^{14}$

This difference could be because of use of different versions of PCNE classification of DRP. It is important to note that Ma SN et al., used PCNE version 5.01 that categorizes the DRPs differently than PCNE version 8.02 as used in our study. Similar to our findings, a study conducted among hospitalized COPD patients also reports treatment safety as the most frequent category of DRPs followed by treatment effectiveness. ${ }^{19}$ In a recent study conducted among hospitalized cancer pain patients, using PCNE version 9.0 classification of DRPs, treatment effectiveness was reported as the most frequent category of DRPs. ${ }^{21}$

Further, in this study we observed that the adverse drug reactions [83/191, (43.5\%)] was the major problems related to the DRPs. This finding was compared with a recent retrospective study that reported

Table 2

Clinical characteristics of the study participants $(n=320)$.

\begin{tabular}{|c|c|c|c|c|}
\hline Variables & Parameters & Intervention group $[\mathrm{n}=160,(100 \%)]$ & Usual care group $[\mathrm{n}=160,(100 \%)]$ & Total $[\mathrm{n}=320(100 \%)]$ \\
\hline \multirow[t]{2}{*}{ Polypharmacy } & $\leq 5$ drugs & $32(20 \%)$ & $44(27.5 \%)$ & $76(23.7 \%)$ \\
\hline & $>5$ drugs & $128(80 \%)$ & $116(72.5 \%)$ & $244(76.2 \%)$ \\
\hline \multirow[t]{3}{*}{ Disease duration } & $<1$ year & $29(18.1 \%)$ & $33(20.6 \%)$ & $62(19.3 \%)$ \\
\hline & $1-5$ year & $75(46.8 \%)$ & $86(53.7 \%)$ & $161(50.3 \%)$ \\
\hline & $>5$ year & $56(35 \%)$ & $41(25.6 \%)$ & $97(30.3 \%)$ \\
\hline \multirow[t]{2}{*}{ Length of hospitalization } & $\leq 5$ days & $70(43.7 \%)$ & $78(48.7 \%)$ & $152(47.5 \%)$ \\
\hline & $>5$ days & $90(56.2 \%)$ & $82(51.2 \%)$ & $168(52.5 \%)$ \\
\hline \multirow[t]{2}{*}{ Number of comorbidities } & $<3$ & $82(51.2 \%)$ & $91(56.8 \%)$ & $173(54.1 \%)$ \\
\hline & $\geq 3$ & $78(48.2 \%)$ & $69(43.1 \%)$ & $147(45.9 \%)$ \\
\hline \multirow[t]{10}{*}{ Common comorbidities } & Hyperlipidaemia & $75(46.8 \%)$ & $62(38.7 \%)$ & $137(42.8 \%)$ \\
\hline & Hypertension & $41(25.6 \%)$ & $49(30.6 \%)$ & $90(28.1 \%)$ \\
\hline & Type 2 diabetes & $42(26.2 \%)$ & $38(23.7 \%)$ & $80(25 \%)$ \\
\hline & Cardiovascular disease & $20(12.5 \%)$ & $27(16.8 \%)$ & $47(14.7 \%)$ \\
\hline & Hypothyroidism & $17(10.6 \%)$ & $22(13.7 \%)$ & $39(12.2 \%)$ \\
\hline & Anaemia & $26(16.2) \%$ & $20(12.5 \%)$ & $46(14.3 \%)$ \\
\hline & Respiratory disease & $23(14.3 \%)$ & $17(10.6 \%)$ & $40(12.5 \%)$ \\
\hline & Renal impairment & $25(15.6 \%)$ & $17(10.6 \%)$ & $42(13.1 \%)$ \\
\hline & Hepatic impairment & $14(8.7 \%)$ & $09(5.6 \%)$ & $23(7.2 \%)$ \\
\hline & Psychosis & $02(1.2 \%)$ & $05(3.1 \%)$ & $07(2.2 \%)$ \\
\hline
\end{tabular}

* All differences were not statistically significant $(\mathrm{p}>0.05)$. 
Table 3

The details of various categories and causes of DRPs identified in the study population.

\begin{tabular}{|c|c|c|c|c|c|}
\hline \multicolumn{6}{|c|}{ Categories of identified DRPs: } \\
\hline Primary domain & Subdomain code & Nature of DRPs & Intervention group & Usual care group & Total \\
\hline \multirow{3}{*}{$\begin{array}{l}\text { Treatment } \\
\text { effectiveness }\end{array}$} & P1.1 & No effect of drug treatment & $28(11.5 \%)$ & $20(9 \%)$ & $48(10.3 \%)$ \\
\hline & $\mathrm{P} 1.2$ & Effect of drug treatment not optimal & $38(15.7 \%)$ & $42(19 \%)$ & $80(17.2 \%)$ \\
\hline & P1.3 & Untreated symptoms or indication & $30(12.3 \%)$ & $25(11.3 \%)$ & $55(11.8 \%)$ \\
\hline Treatment safety & P2.1 & Adverse drug event (possibly) occurring & $101(41.7 \%)$ & $90(40.7 \%)$ & $191(41.2 \%)$ \\
\hline \multirow[t]{3}{*}{ Others } & P3.1 & Problem with cost-effectiveness of the treatment & $25(10.3 \%)$ & $21(9.5 \%)$ & $46(9.9 \%)$ \\
\hline & P3.2 & Unnecessary drug treatment & $20(8.2 \%)$ & $23(10.4 \%)$ & $43(9.2 \%)$ \\
\hline & & Total number of DRPs & $n=242(100 \%)$ & $\mathrm{n}=\mathbf{2 2 1}(\mathbf{1 0 0 \% )}$ & $\begin{array}{l}n=463 \\
(100 \%)\end{array}$ \\
\hline \multicolumn{6}{|c|}{$\overline{\text { Causes of identified DRPs: }}$} \\
\hline Primary domain & $\begin{array}{l}\text { Subdomain } \\
\text { code }\end{array}$ & Nature of causes & $\begin{array}{l}\text { Intervention } \\
\text { group }\end{array}$ & $\begin{array}{l}\text { Usual care } \\
\text { group }\end{array}$ & Total \\
\hline \multirow{7}{*}{ Drug selection } & $\mathrm{C} 1.1$ & Inappropriate drug according to guidelines/formulary & $0(0 \%)$ & $1(0.3 \%)$ & $1(0.1 \%)$ \\
\hline & $\mathrm{C} 1.2$ & $\begin{array}{l}\text { Inappropriate drug (within guidelines but otherwise contra- } \\
\text { indicated) }\end{array}$ & $2(0.7 \%)$ & $3(1.1 \%)$ & $5(0.9 \%)$ \\
\hline & $\mathrm{C} 1.3$ & No indication for drug & $12(4.3 \%)$ & $8(3.2 \%)$ & $20(3.7 \%)$ \\
\hline & C1.4 & Inappropriate combination of drugs or drugs and herbal medication & $17(6.1 \%)$ & $18(7.2 \%)$ & $35(6.6 \%)$ \\
\hline & C1.5 & Inappropriate duplication of therapeutic group or active ingredient & $8(2.8 \%)$ & $9(3.5 \%)$ & $17(3.2 \%)$ \\
\hline & C1.6 & No drug treatment in spite of existing indication & $20(7.2 \%)$ & $15(5.9 \%)$ & $35(6.6 \%)$ \\
\hline & $\mathrm{C} 1.7$ & Too many drugs prescribed for indication & $11(3.9 \%)$ & $8(3.1 \%)$ & $19(3.5 \%)$ \\
\hline Drug form & $\mathrm{C} 2.1$ & Inappropriate drug form (for this patient) & $2(0.7 \%)$ & $0(0 \%)$ & $2(0.3 \%)$ \\
\hline \multirow[t]{5}{*}{ Dose selection } & C3.1 & Drug dose too low & $12(4.3 \%)$ & $9(3.5 \%)$ & $21(3.9 \%)$ \\
\hline & C3.2 & Drug dose too high & $3(1.1 \%)$ & $5(1.9 \%)$ & $8(1.5 \%)$ \\
\hline & C3.3 & Dosage regimen not frequent enough & $5(1.8 \%)$ & $2(0.7 \%)$ & $7(1.3 \%)$ \\
\hline & C3.4 & Dosage regimen too frequent & $3(1.1 \%)$ & $5(1.9 \%)$ & $8(1.5 \%)$ \\
\hline & C3.5 & Dose timing instructions wrong, unclear or missing & $4(1.4 \%)$ & $8(3.1 \%)$ & $12(2.2 \%)$ \\
\hline \multirow[t]{2}{*}{ Treatment duration } & C4.1 & Duration of treatment too short & $15(5.4 \%)$ & $12(4.7 \%)$ & $27(5.1 \%)$ \\
\hline & C4.2 & Duration of treatment too long & $8(2.8 \%)$ & $7(2.7 \%)$ & $15(2.8 \%)$ \\
\hline \multirow[t]{4}{*}{ Dispensing } & C5.1 & Prescribed drug not available & $5(1.8 \%)$ & $9(3.5 \%)$ & $14(2.6 \%)$ \\
\hline & C5.2 & Necessary information not provided & $3(1.1 \%)$ & $4(1.5 \%)$ & $7(1.3 \%)$ \\
\hline & C5.3 & Wrong drug, strength or dosage advised (OTC) & $1(0.3 \%)$ & $3(1.1 \%)$ & $4(0.7 \%)$ \\
\hline & C5.4 & Wrong drug or strength dispensed & $10(3.6 \%)$ & $8(3.1 \%)$ & $18(3.4 \%)$ \\
\hline \multirow[t]{5}{*}{ Drug use process } & C6.1 & Inappropriate timing of administration and/or dosing interval & $24(8.6 \%)$ & $21(8.3 \%)$ & $45(8.5 \%)$ \\
\hline & C6.2 & Drug under-administered & $15(5.4 \%)$ & $10(3.9 \%)$ & $25(4.7 \%)$ \\
\hline & C6.3 & Drug over-administered & $7(2.5 \%)$ & $6(2.3 \%)$ & $13(2.4 \%)$ \\
\hline & C6.4 & Drug not administered at all & $4(1.4 \%)$ & $9(3.5 \%)$ & $13(2.4 \%)$ \\
\hline & C6.5 & Wrong drug administered & $4(1.4 \%)$ & $4(1.5 \%)$ & $8(1.5 \%)$ \\
\hline \multirow[t]{6}{*}{ Patient related } & C7.1 & $\begin{array}{l}\text { Patient uses/takes less drug than prescribed or doesn't take the drug } \\
\text { at all }\end{array}$ & $16(5.7 \%)$ & $12(4.7 \%)$ & $28(5.3 \%)$ \\
\hline & $\mathrm{C} 7.2$ & Patient uses/takes more drug than prescribed & $14(5 \%)$ & $15(5.9 \%)$ & $29(5.4 \%)$ \\
\hline & C7.4 & Patient uses unnecessary drug & $18(6.4 \%)$ & $12(4.7 \%)$ & $30(5.6 \%)$ \\
\hline & C7.7 & Inappropriate timing or dosing intervals & $21(7.5 \%)$ & $17(6.7 \%)$ & $38(7.1 \%)$ \\
\hline & C7.8 & Patient administers/uses the drug in a wrong way & $11(3.9 \%)$ & $8(3.1 \%)$ & $19(3.5 \%)$ \\
\hline & C7.9 & Patient unable to use drug/form as directed & $2(0.7 \%)$ & $3(1.1 \%)$ & $5(0.9 \%)$ \\
\hline \multicolumn{3}{|c|}{ Total number of causes (one DRP may have one or more causes)* } & $\mathrm{n}=\mathbf{2 7 7}(\mathbf{1 0 0} \%)$ & $\mathrm{n}=251(100 \%)$ & $\begin{array}{l}n=528 \\
(100 \%)\end{array}$ \\
\hline
\end{tabular}

DRPs: Drug-related problems; PCNE: Pharmaceutical Care Network Europe; OTC: Over-the-counter drugs.

adverse reactions as the major [112, 38.8\%] problems for DRPs among RA patients. ${ }^{14}$ This indicates that adverse drug reaction is more common problem associated with the drug therapy in modern medical practice. This may depend on drug and dose selection, alteration in drug use process, polypharmacy, drug interaction and changes in body physiology. Thus, these findings suggest that the RA patients are in need of adequate screening by the clinical pharmacists and treating physicians, for the possible risks of adverse drug events.

The most frequent causes of DRPs were related to the patient noncompliance [149/528, 28.2\%] and drug selection [132/528, 25\%]. In a previously conducted study by Ma SN et al., the causes of DRPs were not adequately reported among RA patients. ${ }^{14}$ However, Zhu Y et al., reported similar causes of DRPs, indicating patient related [127/492, $25.8 \%$ ] and drug selection [118/492, 24\%], as observed in the present study. ${ }^{22}$ The patient related contributing factors were frequent because of multiple drug therapy, lack of patients' knowledge and monitoring and long duration of drug therapy. This indicates that the prescriber and clinical pharmacist need to critically evaluate the patient or patient's care taker knowledge about drug use. Similarly, the prescribers must ensure that the selected drug is appropriate for the given patient and clinical situation and patients is able to take the drugs as prescribed. Therefore, involvement of patient and their care takers is vital in drug selection process.

An intervention is any action by a clinical pharmacist that directly results in a change in patient management or therapy. ${ }^{23}$ This is the first clinical pharmacist-led study among RA patients that suggested the interventions to all the identified DRPs and assessed its impact upon implementation. A majority (91.3\%) of clinical pharmacist proposed interventions were accepted by the concerned personnel. This study finding was compared with a similar study conducted in an acute internal medicine ward by Lombardi $\mathrm{N}$ et al., reported a similar acceptance rate $(93.2 \%)$ of clinical pharmacist proposed intervention by physicians. ${ }^{24}$ Salman B et al. also reported $95 \%$ of clinical pharmacist proposed interventions were accepted by physicians. ${ }^{25}$ This finding indicates that the clinical pharmacist provided interventions to resolve DRPs were highly appreciating and accepting by the physicians in modern clinical practice.

However, twenty-four (8.7\%) clinical pharmacist interventions were not accepted leading to the seventeen DRPs remained unresolved. The reasons for non-acceptance were lack of physician confidence towards 
Table 4

Risk factor associated with the development of DRPs among study participants.

\begin{tabular}{|c|c|c|c|c|c|}
\hline \multirow[t]{2}{*}{ Variables } & \multirow[t]{2}{*}{ Parameters } & \multicolumn{2}{|c|}{$\begin{array}{c}\text { Drug } \\
\text { related } \\
\text { problems }\end{array}$} & \multirow[t]{2}{*}{ OR at $95 \% \mathrm{Cl}^{*}$} & \multirow[t]{2}{*}{$P$ value } \\
\hline & & Yes & No & & \\
\hline \multirow[t]{2}{*}{ Gender } & Male & 63 & 9 & 1 & \\
\hline & Female & 220 & 28 & $\begin{array}{l}1.12 \\
(0.50-2.50)\end{array}$ & 0.77 \\
\hline \multirow{5}{*}{$\begin{array}{l}\text { Age distribution (in } \\
\text { years) }\end{array}$} & $<19$ & 13 & 9 & 1 & \\
\hline & $19-40$ & 86 & 12 & $\begin{array}{l}4.58 \\
(1.79-11.70)\end{array}$ & 0.0014 \\
\hline & $41-60$ & 120 & 10 & $\begin{array}{l}8.30 \\
(2.85-24.14)\end{array}$ & 0.0001 \\
\hline & $61-80$ & 51 & 4 & $\begin{array}{l}8.82 \\
(2.34-33.23)\end{array}$ & 0.0013 \\
\hline & $>80$ & 13 & 2 & $\begin{array}{l}4.50 \\
(0.81-24.98)\end{array}$ & 0.085 \\
\hline \multirow[t]{3}{*}{ BMI $\left(\mathrm{Kg} / \mathrm{m}^{2}\right)$} & $\leq 18.5-24.9$ & 108 & 22 & 1 & - \\
\hline & $25-29.9$ & 132 & 9 & $\begin{array}{l}2.98 \\
(0.41-3.68)\end{array}$ & 0.008 \\
\hline & $\geq 30$ & 43 & 6 & $\begin{array}{l}1.45 \\
(0.55-3.84)\end{array}$ & 0.444 \\
\hline \multirow[t]{2}{*}{ Polypharmacy } & $\leq 5$ drugs & 52 & 24 & 1 & - \\
\hline & $>5$ drugs & 231 & 13 & $\begin{array}{l}8.20 \\
(3.91-17.17)\end{array}$ & $<0.0001$ \\
\hline \multirow[t]{2}{*}{ Length of hospital } & $\leq 5$ days & 125 & 27 & 1 & - \\
\hline & $>5$ days & 158 & 10 & $\begin{array}{l}3.59 \\
(1.59-7.31)\end{array}$ & 0.0016 \\
\hline \multirow{2}{*}{$\begin{array}{l}\text { Number of } \\
\text { comorbidities }\end{array}$} & $<3$ & 142 & 31 & 1 & - \\
\hline & $\geq 3$ & 141 & 6 & $\begin{array}{l}5.13 \\
(2.07-12.67)\end{array}$ & 0.0004 \\
\hline
\end{tabular}

Multivariate logistic regression analysis applied at 95\% CI. *OR: Odds ratio, CI: Confidential interval, $P<0.05$ considered as statistically significant.

suggested pharmacist interventions, inability of patient to bear the treatment cost of new medication, physician willingness to continue the same treatment, and delay in communication with concerned healthcare personnel and lack of drug availability.

Most (45\%) of the accepted clinical pharmacist interventions were of moderate clinical significance indicating requirement of adjustments to enhance drug therapy efficacy or less than $20 \%$ chance of noticed effect. A study conducted in the internal medicine unit also reported that the majority $(63.2 \%)$ of the interventions were of moderate severity. ${ }^{24}$

In this study, accepted clinical pharmacist interventions were implemented and led to resolution of $96.4 \%$ DRPs. Our study finding are comparable with a study that reported $81.9 \%$ resolution of DRPs among patients with respiratory disorders. ${ }^{22}$ This difference could be due to implementation of less number of accepted interventions (85.6\%) leading to resolution of less number of DRPs as compared to our study.

We observed that RA patients with increase in age are at increased risk of developing DRPs. This could be due to multiple drug therapy because of concurrent clinical conditions. However, our findings are inconsistent with a study that reported no association between increase in age and occurrence of DRPs. ${ }^{14}$ Patient with polypharmacy and multiple comorbidities $(\geq 3)$ were also associated with the increased risk of DRPs. These finding was consistent with the other studies. ${ }^{14,24,26}$ Presence of multiple comorbidities results in polypharmacy as observed in our study. This could be justified by complexity of drug therapy, resulting from multiple comorbidities and that increases the risk of DRPs. Further, development of DRPs could be enhance as the polypharmacy increases the risk of patients' non-compliance towards prescribed drug therapy. This may result in increased length of hospital stay, organ impairment and economic burden. Therefore, clinical pharmacist and prescriber needs to be vigilant in screening the possible risk factors that could contribute in the development of DRPs. We conclude that the prevalence of DRPs is common among RA patients, and the clinical pharmacist-led MDCT provided patient care had a high impact on DRPs resolution rate. Therefore, clinical pharmacists can play a vital role in identifying and resolving the DRPs among RA patients. Pharmacists are at a right position to support individualized patient care by adequately reviewing the medications and providing suitable solutions that can promote safe and effective use of medications among RA patients. ${ }^{27,28}$

\section{Financial support}

Nil.

\section{Declaration of competing interest}

There are no conflicts of interest.

\section{References}

1 Sah SK, Subramanian R, Ramesh M. Methotrexate-induced organ toxicity in patients with rheumatoid arthritis: a review article. Drug Invent Today. 2020;14:137-152.

2 Guo Q, Wang Y, Xu D, Nossent J, Pavlos NJ, Xu J. Rheumatoid arthritis: pathological mechanisms and modern pharmacologic therapies. Bone Res. 2018;6:1-14. https:// doi.org/10.1038/s41413-018-0016-9.

3 Kumar AA, Gupta K, K S, Kumar SA. Clinical profile of rheumatoid arthritis patients reporting to a tertiary care center - data from southwestern part of India. Int $J$ Contemp Med Res. 2019;6:26-32. https://doi.org/10.21276/ijcmr.2019.6.6.49.

4 Handa R, Rao URK, Lewis JFM, Rambhad G, Shiff S, Ghia CJ. Literature review of rheumatoid arthritis in India. Int J Rheum Dis. 2016;19:440-451. https://doi.org/ 10.1111/1756-185X.12621.

5 Maeda Y, Takeda K. Role of gut microbiota in rheumatoid arthritis. J Clin Med. 2017; 6:60. https://doi.org/10.3390/jcm6060060.

6 Alwarith J, Kahleova H, Rembert E, et al. Nutrition interventions in rheumatoid arthritis: the potential use of plant-based diets. A review. Front Nutr. 2019;6:1-11. https://doi.org/10.3389/fnut.2019.00141.

7 Bullock J, Rizvi SAA, Saleh AM, et al. Rheumatoid arthritis: a brief overview of the treatment. Med Princ Pract. 2018;27:501-507. https://doi.org/10.1159/000493390.

8 Kohler BM, Günther J, Kaudewitz D, Lorenz H-M. Current therapeutic options in the treatment of rheumatoid arthritis. J Clin Med. 2019;8:1-15. https://doi.org/ $10.3390 /$ jcm8070938.

9 Roy DA, Shanfar I, Shenoy P, Chand S. Drug-related problems among chronic kidney disease patients : a clinical pharmacist led study. Int J Pharm Res. 2020;12:79-84. https://doi.org/10.31838/ijpr/2020.12.04.017.

10 Garin N, Sole N, Lucas B, et al. Drug related problems in clinical practice: a cross sectional study on their prevalence, risk factors and associated pharmaceutical interventions. Sci Rep. 2021;11:1-11. https://doi.org/10.1038/s41598-020-80560-2.

11 Voora L, Sah SK, Bhandari R, et al. Doctor of pharmacy: boon for health-care system. Drug Invent Today. 2020;14:153-158.

12 Stuhec M, Gorenc K, Zelko E. Evaluation of a collaborative care approach between general practitioners and clinical pharmacists in primary care community settings in elderly patients on polypharmacy in Slovenia: a cohort retrospective study reveals positive evidence for implementation. BMC Health Serv Res. 2019;19:1-9. https:// doi.org/10.1186/s12913-019-3942-3.

13 Zaal RJ, den Haak EW, Andrinopoulou ER, van Gelder T, Vulto AG, van den Bemt PMLA. Physicians' acceptance of pharmacists' interventions in daily hospital practice. Int J Clin Pharm. 2020;42:141-149. https://doi.org/10.1007/s11096-02000970-0.

14 Ma SN, Huri HZ, Yahya F. Drug-related problems in patients with rheumatoid arthritis. Therapeut Clin Risk Manag. 2019;15:505-524. https://doi.org/10.2147/ TCRM.S194921.

15 Singh JA, Saag KG, Bridges SLJ, et al. 2015 American college of rheumatology guideline for the treatment of rheumatoid arthritis. Arthritis Care Res. 2016;68:1-26. https://doi.org/10.1002/art.39480.

16 Bornstein C, Craig M, Tin D. Practice guidelines for pharmacists: the pharmacological management of rheumatoid arthritis with traditional and biologic disease-modifying antirheumatic drugs. Can Pharm J. 2014;147:97-109. https://doi.org/10.1177/ 1715163514521377.

17 Pharmaceutical Care Network Europe. Classification for drug related problems: the PCNE classification V 8.02. Pharm Care Netw Eur Assoc; 2019. V8.02:3 https://www. pcne.org/upload/files/318_PCNE_classification_V8-03.pdf.

18 Alderman CP. A prospective analysis of clinical pharmacy interventions on an acute psychiatric inpatient unit. J Clin Pharm Therapeut. 1997;22:27-31. https://doi.org/ 10.1046/j.1365-2710.1997.95975959.x.

19 Li Q, Qu HJ, Lv D, et al. Drug-related problems among hospitalized patients with COPD in mainland China. Int J Clin Pharm. 2019;41:1507-1515. https://doi.org/ 10.1007/s11096-019-00913-4.

20 Susilawati NM, Halimah E, Saidah S. Pharmacists' strategies to detect, resolve, and prevent DRPs in CKD patients. Pharmacia. 2021;68:619-626. https://doi.org/ 10.3897/pharmacia.68.e65136.

21 Su YJ, Yan YD, Wang WJ, et al. Drug-related problems among hospitalized cancer pain patients: an investigative single-arm intervention trial. Ann Palliat Med. 2021; 10:2008-2017. https://doi.org/10.21037/apm-20-1458. 
22 Zhu Y, Liu C, Zhang Y, et al. Identification and resolution of drug-related problems in a tertiary hospital respiratory unit in China. Int J Clin Pharm. 2019;41:1570-1577. https://doi.org/10.1007/s11096-019-00922-3.

23 G P A. Text Book of Clinical Pharmacy Practice: Essential Concepts and Skills. second ed. Universities Press; 2012

24 Lombardi N, Wei L, Ghaleb M, et al. Evaluation of the implementation of a clinical pharmacy service on an acute internal medicine ward in Italy. BMC Health Serv Res. 2018;18:1-9. https://doi.org/10.1186/s12913-018-2988-y.

25 Salman B, Al-Hashar A, Al-Khirbash A, Al-Zakwani B. Clinical and cost implications of clinical pharmacist interventions on antimicrobial use at sultan Qaboos University hospital in Oman. Int J Infect Dis. 2021;109:137-141.
26 Saldanha V, de Araújo IB, Vieira Cunha Lima SI, Randall Martins R, Oliveira AG. Risk factors for drug-related problems in a general hospital: a large prospective cohort. PLoS One. 2020;15:1-16. https://doi.org/10.1371/journal.pone.0230215.

27 Lee EM, Vasudevan AR, Wee IYJ, Yeow SD, Dinh VTU. Effectiveness and safety of physician-pharmacist collaborative care for rheumatoid arthritis patients: the Changi General Hospital's experience. Proc Singapore Healthc. 2019;28:184-192. https://doi.org/10.1177/2010105819839078.

28 Sah SK RS, Ramesh M, Chand S. Impact of pharmacist care in the management of autoimmune disorders: a systematic review of randomized control trials and nonrandomized studies. Res Soc Adm Pharm. 2021;17:1532-1545. https://doi.org/ 10.1016/j.sapharm.2020.12.005. 